\title{
Las redes de la vivienda y el desarrollo sustentable en la centralidad de las ciudades de Oaxaca, México, 2000-2015
}

\section{Housing networks and sustainable development in centrality of the cities in Oaxaca, Mexico, 2000-2015}

\author{
Andrés Enrique Miguel-Velasco ${ }^{\mathrm{a}}$ \\ Karina Aidee Martínez García ${ }^{b}$ \\ Maribel Pérez Pérez ${ }^{c}$ \\ María del Rosario Moncada García ${ }^{\mathrm{d}}$
}

\begin{abstract}
Resumen
A partir del concepto de "vivienda adecuada", se analiza la influencia de la vivienda en el desarrollo sustentable de las principales ciudades de Oaxaca con más de 15000 habitantes, suponiendo que el crecimiento de la vivienda favorece el desarrollo de los centros urbanos a través de la creación de "lugares centrales". Mediante la metodología de regresión lineal y el análisis de redes, el trabajo permite concluir que la construcción de la vivienda se ha incrementado durante 2000-2015, pero con una muy baja contribución, dado que su efecto no ha generado centralidad en el territorio, por lo cual se requiere una revisión de las políticas públicas.
\end{abstract}

Palabras clave: vivienda; ciudades; Oaxaca; red urbana.

a Profesor investigador del Instituto Tecnológico de Oaxaca, División de Estudios de Posgrado e Investigación. Dirección postal: Av. Ing. Víctor Bravo Ahuja 125, 68030, Oaxaca, Oaxaca, México. Correo electrónico: andres.miguel@itoaxaca.edu.mx

${ }^{\mathrm{b}}$ Estudiante de la maestría en Ciencias en Desarrollo Regional y Tecnológico en el Instituto Tecnológico de Oaxaca, México. Dirección postal: Av. Ing. Víctor Bravo Ahuja 125, 68030, Oaxaca, Oaxaca, México. Correo electrónico: aidee1005@hotmail.com

${ }^{\mathrm{c}}$ Estudiante del doctorado en Ciencias en Desarrollo Regional y Tecnológico en el Instituto Tecnológico de Oaxaca, México. Dirección postal: Av. Ing. Víctor Bravo Ahuja 125, 68030, Oaxaca, Oaxaca, México. Correo electrónico: mary01758@hotmail.com

${ }^{d}$ Estudiante del doctorado en Ciencias en Desarrollo Regional y Tecnológico en el Instituto Tecnológico de Oaxaca, México. Dirección postal: Av. Ing. Víctor Bravo Ahuja 125, 68030, Oaxaca, Oaxaca, México. Correo electrónico: mogrosario@hotmail.com 


\begin{abstract}
Based on the concept of "adequate housing", the analysis focuses on the housing influence in the sustainable development of the main cities of Oaxaca greater than 15000 inhabitants, assuming that increased housing favors the development of our urban centers, by the creation of "central places". Through a methodology of linear regression and network analysis, the results suggest that housing construction has increased during 2000-2015, but with a low contribution, because its impacts don't generate the centrality in the territory, for which reason it's required a review of the public policies.
\end{abstract}

Keywords: housing; cities; Oaxaca; urban network.

\title{
1. Introducción
}

A lo largo del tiempo la ciencia regional ha propuesto explicaciones sobre la estructuración socioeconómica y ambiental de las regiones y las ciudades, pasando de lo simple a lo complejo. En sus inicios la problemática analizada se delimitó a la especialización, el crecimiento económico, la obtención de ganancias y la localización de empresas e inversiones a nivel espacial (caso del "paradigma de la localización"). En un segundo gran salto teóricometodológico pasó a explicar el crecimiento económico y el desarrollo económico, dando origen al "paradigma del desarrollo" (Miguel, 2011). En la actualidad, la problemática de las regiones impulsa la ciencia regional hacia "el bienestar basado en la complejidad". Con base en este paradigma, explica su problemática de manera multicausal, multifuncional, multidisciplinaria e interregional, incluyendo variables económico-sociales, ambientales, territoriales, infraestructura, servicios, etc., con la finalidad de proponer políticas públicas específicas para mejorar el bienestar y la calidad de vida de la población (Miguel, 2011). El análisis de las redes territoriales urbanas y rurales cae en esta consideración.

El estudio de las redes es una manifestación del comportamiento social, e incluye aportes de diversos campos como la economía, la sociología y la administración, así como el conocimiento urbano-regional. Proporciona herramientas teórico-metodológicas para el análisis de las ciudades y regiones, centrándose en la asociación y medida de las relaciones y flujos entre las personas y las organizaciones de ciudades, etc., ya que los nodos en las redes territoriales son precisamente las ciudades y las localidades, y sus enlaces muestran las relaciones entre ellas. Una parte del análisis de redes se fundamenta en las medidas de centralidad de los actores de la red territorial, sus lugares centrales, con el objetivo de detectar las relaciones, comu- 
nidades y clústeres espaciales, etc. Los lugares centrales determinan la jerarquía de los asentamientos urbanos, estableciendo el grado de influencia de una ciudad, localidad en el territorio o la estructura territorial donde se localizan. Las ciudades, cuando ejercen la función de lugar central, generan una interacción derivada de las asociaciones entre las propias urbes, que determina su jerarquía y, por consiguiente, su capacidad para impulsar las diversas actividades requeridas por el desarrollo de la población de las propias ciudades.

En los lugares centrales la importancia económica de la vivienda para el bienestar social y familiar es innegable, ya que según el CEDRUS (2016), en México el 75\% del uso del suelo corresponde a la misma. Además, es uno de los principales activos que forman el patrimonio de las familias, que en lo general lo consideran un ahorro e inversión para preservar sus recursos. En este sentido, una "vivienda adecuada" es más que un techo bajo el cual protegerse. Para Naciones Unidas significa disponer de un lugar con privacidad, espacio suficiente, accesibilidad física, seguridad, tenencia legal, estabilidad y durabilidad estructurales, iluminación, calefacción y ventilación; una infraestructura básica que incluya servicios de abastecimiento de agua, saneamiento y eliminación de desechos; factores apropiados de calidad del medio ambiente y de salud; así como un emplazamiento con acceso a fuentes de trabajo y a los servicios básicos, todo ello a un costo razonable (ONU, 1996).

En este contexto teórico-metodológico, el presente artículo analiza el nivel de influencia de la vivienda en el desarrollo sustentable y la centralidad de las ciudades de Oaxaca con población mayor a 15000 habitantes. Las hipótesis a comprobar son que durante el periodo 2000-2015 existe una correlación alta y significativa: 1) entre el índice de construcción de vivienda y el índice de desarrollo sustentable de las ciudades de Oaxaca; y 2) que esta correlación permite que existan ciudades que ejercen la función de "lugares centrales" derivados de la actividad de la vivienda, considerando de manera específica que las urbes de mayor tamaño, concretamente las zonas metropolitanas del estado de Oaxaca, México, ejercen la función de "lugar central" en la red de ciudades analizadas; es decir, que poseen la mayor centralidad derivada de la actividad de la vivienda en su territorio. 


\section{Marco conceptual}

\subsection{El desarrollo sustentable, la vivienda y las redes en las ciudades}

La ciudad es el centro territorial de la acumulación de capital, el instrumento colectivo de la reproducción social, el centro espacial de la distribución e intercambio de mercancías (Casado, 2010), y el modo específico más favorable de usar el espacio, de ordenarlo y planificarlo, para la producción económica y el bienestar de la población en las diversas regiones. La mayor parte de las veces su expansión espacial es explicada por la creación de viviendas en su territorio; tal expansión puede propiciar el desarrollo sustentable de las propias ciudades, entendiendo éste como el logro armónico del bienestar económico, social y ambiental de la población que las habita.

El concepto de vivienda analizado por autores como Michelle Ball, Luis Cortés, Judith Villavicencio, Edwin Haramoto y Priscilla Connolly posee implícitos aspectos culturales determinados por un contexto histórico-social que dificultan entenderlo de una forma única. La palabra vivienda provoca en las personas una inmediata representación esquemática relacionada con el hábitat (Rugiero, 2000). La relación que muestra el desarrollo con la vivienda se fundamenta en la concentración territorial de ésta en las ciudades, y puede considerarse que su aglomeración consolida y promueve el desarrollo, e influye también en el medio ambiente, dificultando en ocasiones la sustentabilidad de las propias ciudades. En el Cuadro 1 se muestran las teorías de las cuales derivan las variables de la vivienda enfocadas al desarrollo, acompañadas de los autores y organizaciones correspondientes al fundamento de cada enfoque y concepto teórico.

Desde una visión "economicista", la vivienda es un objeto útil para satisfacer las necesidades humanas, pero también es un producto de la fuerza de trabajo que se puede vender o comprar: es una mercancía que se produce por el sector inmobiliario, generado por sus propios ocupantes. En relación a este punto, Schteingart y Solís (1994) argumentan que es un objeto de ganancia para una serie de agentes inmobiliarios y constructores que participan en su proceso de producción y distribución en el mercado, y es también objeto de políticas públicas que tratan de facilitar el acceso a la misma por los sectores menos favorecidos de la sociedad, pero sujetos a crédito, a través de financiamiento a largo plazo.

Como se mencionó en el primer apartado, el concepto de "vivienda adecuada" es el que orienta el análisis de este artículo, e implica una visión compleja, es decir, multifuncional, multicausal e interdisciplinaria, ligada al enfoque del "desarrollo humano", el cual contribuye a identificar la disposición 


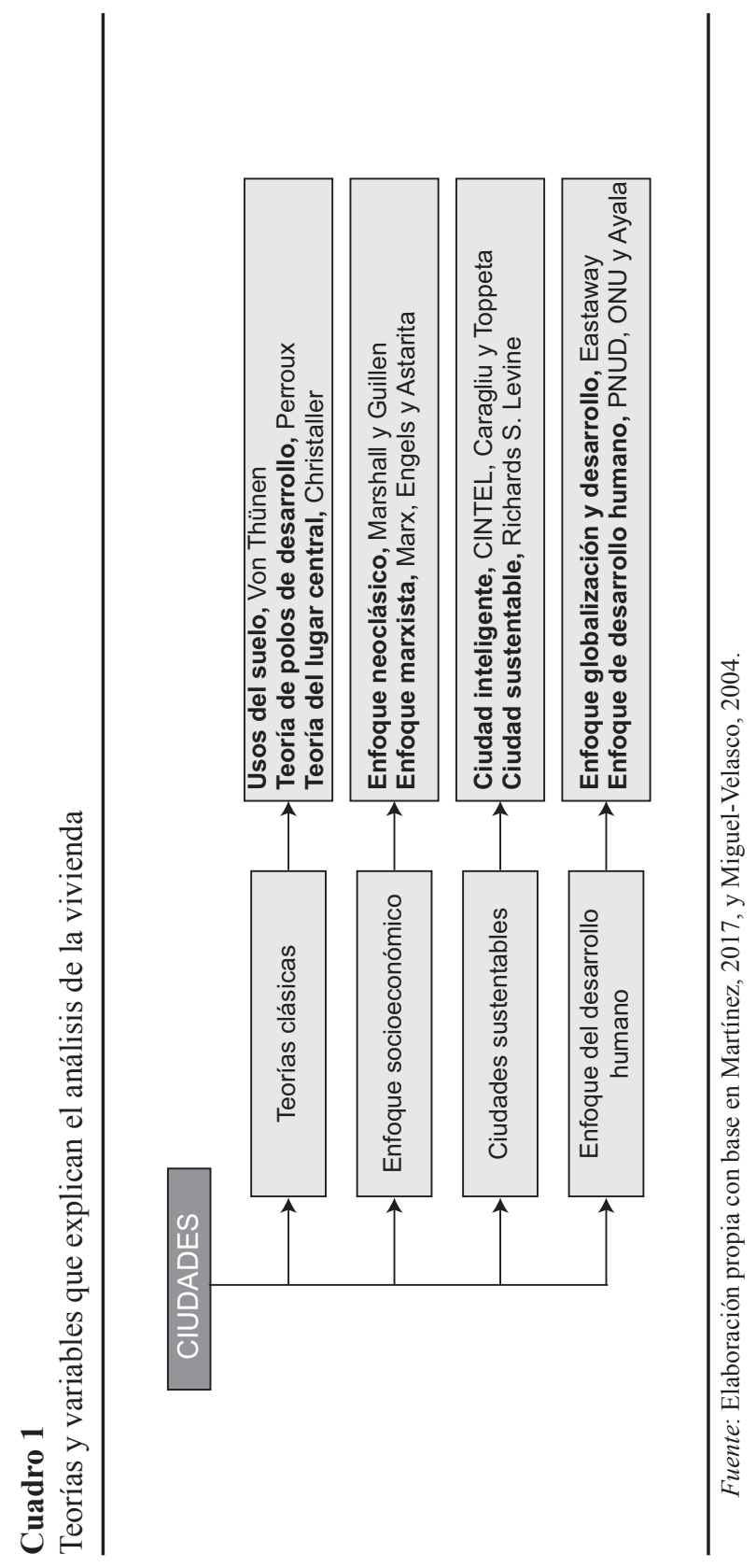


de un alojamiento adecuado y su posibilidad de facilitar un proyecto de vida personal y familiar que garantice el bienestar económico, social y ambiental de la población; es decir, el desarrollo sustentable de la población que habita la red generada por las ciudades.

Según Lamy (2006), la red de urbanización se basa en los diferentes cambios que se generan en el planeta, manifestándose con gran variedad morfológica y cultural, siendo esto un reto para la civilización. En cambio, Clavel (2002) comenta que la ciudad se muestra como "un producto de los hombres en sociedad, como una obra colectiva", y compara tal definición con las de autores como Henri Lefebvre y los neomarxistas, quienes definen la ciudad y lo urbano desde un enfoque social y espacial, como "el corazón de las sociedades contemporáneas, el espacio (social) es un producto (social)".

De igual manera, el desarrollo, en el ámbito territorial, no es un proceso aislado, más bien es resultado de la interacción existente entre las ciudades, las localidades y el territorio de las regiones. Las ciudades consolidan su desarrollo a través de las redes de intercambio de mercancías, de conocimientos, de recursos, etc., que se conforman en la interacción, dando origen a los "lugares centrales" de la red. Se entiende como "lugar central" cualquier centro urbano o ciudad que provee a la población de la máxima cantidad de servicios financieros, comerciales, profesionales y de comunicaciones, instalaciones educativas, recreativas y culturales, servicios públicos urbanos, lo que finalmente se refleja en equipamiento urbano. Las relaciones entre las ciudades de los sistemas urbanos obedecen a criterios jerárquicos; la posición de una urbe en la red está en función de su especialización funcional y su grado de centralidad (capacidad de organizar) las funciones que requiere el desarrollo (Hernández, 2016).

El análisis de las interacciones entre las ciudades se lleva a cabo a través de las redes que éstas conforman. Las urbes se convierten en "lugares centrales" heterogéneos y dinámicos de la red debido a las estructuras socioeconómicas desiguales que poseen y que les provocan múltiples efectos. En cada metrópoli se desarrollan fuerzas de concentración (centralidad hacia adentro), y de dispersión (centralidad hacia afuera), que la modifican permanentemente. En las redes urbanas es posible analizar un conjunto de ciudades como un todo funcionando de manera jerarquizada y dinámica.

$\mathrm{Al}$ respecto, es común evaluar la densidad y la centralización de las redes para definir su comportamiento. En el primer aspecto, se toma como base la densidad de la red, que es una medida de cohesión referida a la cantidad de observaciones respecto al conjunto de relaciones posibles de la red, e indica el nivel de asociación o complejidad existente en las ciudades. Otro indicador, la "centralización", se refiere a las conexiones sobre la dispersión 
y la concentración existentes en la red, y por consiguiente indica la existencia y consolidación de los lugares centrales que posee. En términos analíticos, una mayor centralidad equivale a la existencia de lugares centrales consolidados, más control por parte de éstos, y más dependencia del resto de sus elementos hacia el nodo. Implícitamente, la centralidad de las ciudades sustenta la jerarquía de la mismas, y a su vez ésta expresa el potencial que poseen para impulsar las actividades que requiere su desarrollo. En resumen, la centralidad ocasiona que una ciudad posea más jerarquía en la estructura territorial ligada a su nivel de desarrollo y a las actividades económicas: si una actividad no refuerza o incrementa la centralidad, no es significativa en la ordenación de la estructura urbana.

\subsection{La red urbana y sus conexiones en el desarrollo de las ciudades}

Para conceptualizar la red urbana, Serrano (2000) se basa en B. Cori (1995), quien la define como "la jerarquía general de las ciudades que organizan la vida social de una región". Derivada de términos parecidos al pasar de los años, en 1996 P. Bruyelle la establece como la entidad real que, situada en el territorio, nos sirve de punto de referencia imprescindible, concluyendo que la mutua interdependencia y la continua relación entre la red de ciudades originan los "subsistemas y sistemas urbanos".

Las conexiones en el diseño urbano ligan a tres tipos distintos de elementos: los naturales, los arquitectónicos y los nodos de actividad humana. Los elementos arquitectónicos incluyen todo lo que los seres humanos construyan para conectar elementos naturales y refuercen sus nodos de actividad (Nikos, 2005). Las colonias funcionan sólo si los nodos contrastantes están colocados de tal forma que propicien uniones activas entre nodos similares. Esta es la clave para construir la red urbana: se establecen conexiones múltiples entre nodos complementarios, entonces se agrupan en trayectorias que también conectan nodos iguales. Se necesita un balance entre nodos iguales y opuestos. La Figura 1 muestra cómo las concentraciones excesivas de nodos y conexiones crean singularidad: a) los nodos están concentrados y todas las conexiones están forzadas en dos canales, excediendo la capacidad de carga de los canales; b) la misma cantidad de nodos son distribuidos con conexiones que trabajan mucho mejor (Galán, Casanueva y Castro-Abancéns, 2010). 


\section{Figura 1}

Ejemplo de concentración de dos tipos de nodos

(a)

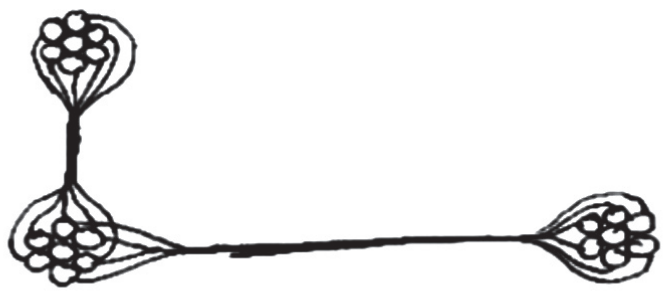

(b)

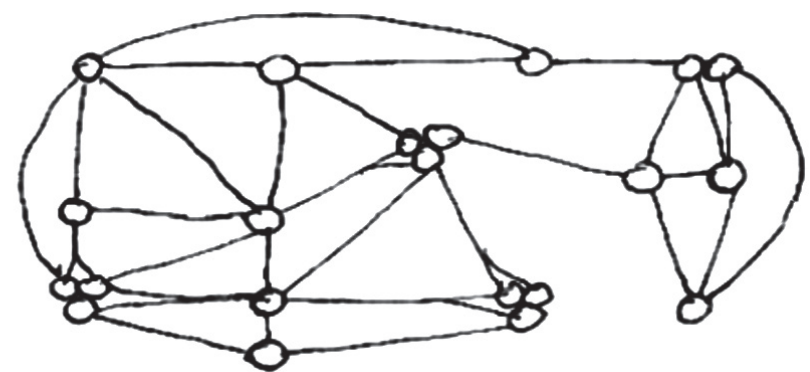

Fuente: Ilustración del artículo "Las relaciones empresariales: una tipología de redes" (Galán, Casanueva y Castro-Abancéns, 2010).

\subsection{Red de ciudades, jerarquía urbana y distribución de la población}

Un trabajo pionero sobre redes y centralidad fue presentado en el libro $E l$ desarrollo urbano de México (Unikel y Necochea, 1971, citado en Sánchez, 2016), en el cual se aplicaron modelos gravitacionales para determinar la posición y el potencial de 38 ciudades (que en 1960 tenían 50 mil o más habitantes). Los resultados indicaron que: a) al aumentar el tamaño de la población de la ciudad aumentaban sus actividades especializadas de importancia regional y nacional, económicas, financieras y culturales; b) en las ciudades de mayor tamaño se encontraban los más altos niveles de vida; c) existía un fuerte centralismo demográfico, social y económico de la Ciudad de México; d) las ciudades de la región centro dependían de la capital del país; e) se observaban subsistemas de ciudades en el Bajío, hacia la costa del Pacífico y alrededor de Veracruz, pero con una integración débil; f) destacaba el aislamiento de ciudades como Mérida, Durango y Villaher- 
mosa, y g) por su potencial sobresalía la Ciudad de México debido a su gran tamaño de población y peso económico, Monterrey por su industria y Acapulco por su importancia turística nacional e internacional (Unikel, Garza y Ruiz, 1978).

Posteriormente, en la primera década de los años 2000, la Secretaría de Desarrollo Social y el Instituto de Investigaciones Económicas de la UNAM elaboraron el documento Estrategia territorial nacional, en el que concluyeron, entre otros resultados, que subsiste un esquema prismático con la Zona Metropolitana del Valle de México en la cúspide del funcionamiento del sistema urbano nacional, pero también emerge una red incipiente de centros urbanos con interacciones de complementariedad y mayor fuerza económica, sobre todo en el Bajío y hacia el noreste del territorio nacional (Sedesol y UNAM, 2000) (véase el Mapa 1).

En el mismo tenor, Sánchez (2016) argumentó que en el ámbito territorial se ha profundizado la desigualdad socioeconómica en la estructura y dinámica del sistema urbano nacional, y que es importante evitar la ampliación de la brecha en el desarrollo entre norte, centro y sur. El sistema urbano nacional presenta una transformación desde el modelo prismático jerárquico de alta concentración hacia la conformación de redes de ciudades, con mayor desconcentración espacial, y el reto de promover una planeación urbanoregional que permita mejorar el nivel de bienestar de la población en cualquier lugar del país.

A inicios de los noventa el Consejo Nacional de Población publicó el libro Sistema de ciudades y distribución espacial de la población en México (Conapo, 1991), en concordancia con los lineamientos del Programa Nacional de Población 1989-1994, considerando el objetivo de orientar la distribución de la población en el país de manera más equilibrada, y enfrentar la concentración y dispersión con propuestas de política de fomento a las pequeñas y medianas ciudades, de acuerdo con su potencial de crecimiento y con variables territoriales de tipo económico, social y de recursos naturales.

Además, se recapacita en torno a que la polarización geográfica ha introducido el problema de inequidad territorial, y que las políticas de ordenamiento del territorio y de desarrollo regional deben "encontrar un equilibrio razonable entre las consideraciones de equidad y distribución espacial de las actividades y su costo en términos de crecimiento global" (Jayet y Thiesse, 1996: 153). Desde esta perspectiva, la forma como los sistemas urbanos se estructuren constituirá un elemento clave (Ferrão, 1998), jugando la edificación de la vivienda un papel fundamental en la construcción y transformación del desarrollo de las redes de ciudades, ya que constituye uno de los eslabones básicos generadores del bienestar y la centralidad de las propias ciudades. 


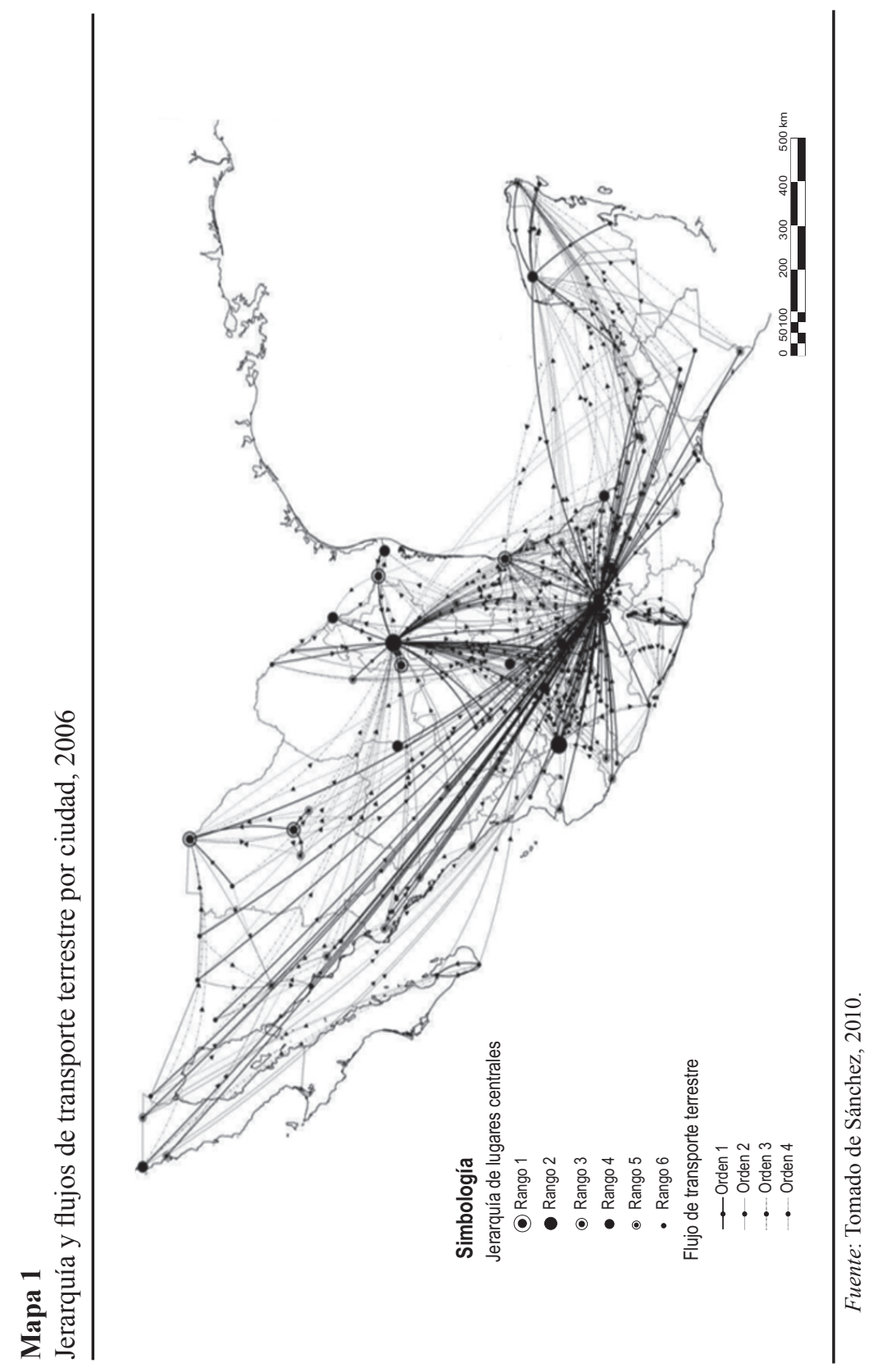




\section{Procedimiento metodológico}

\subsection{Modelo de análisis}

El modelo teórico del presente artículo establece la relación entre la vivienda y el desarrollo en las ciudades durante el periodo 2000-2015. En el Esquema 1 se especifican sus dimensiones económica, social y ambiental.

El modelo propone que un aumento de los indicadores de la vivienda -como la habitabilidad, el financiamiento y los servicios- se refleja en el aumento del desarrollo sustentable, y también en la centralidad de las ciudades. Cabe aclarar que en este modelo no se considera la calidad de las viviendas, el material con el que están construidas, el grado de hacinamiento, ni los riesgos derivados de los lugares donde se construyen, sino que pone énfasis en su construcción.

\subsection{Instrumentos de información}

Se seleccionaron indicadores de población y vivienda de los censos y conteos de población (INEGI, 2000, 2005, 2010 y 2015) para los municipios más urbanizados de Oaxaca, en los cuales se encuentran asentadas las ciudades seleccionadas o los lugares centrales con población mayor de 15000 habitantes. Se eligieron indicadores del desarrollo, en este caso el índice de de-

\section{Esquema 1}

Modelo teórico de la investigación

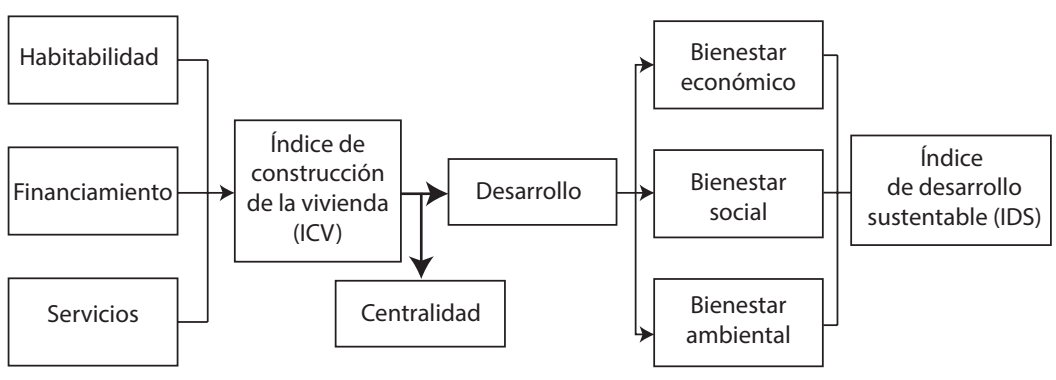

Fuente: Elaboración propia con base en el modelo de la vivienda digna (SIDESCA, 2016). 
sarrollo humano (IDH) y el PIB (PNUD, México, 2014); del consumo de agua por habitante (que es la cantidad del líquido que consume una persona para beber, limpiar, preparar alimentos, y otros usos domésticos), y sobre la generación de residuos sólidos (Gobierno de Oaxaca, 2012). En el Cuadro 2 se enuncian las variables detalladas y se especifican sus dimensiones, indicadores y ecuaciones correspondientes.

La valoración de los índices de desarrollo humano y desarrollo sustentable se consideran bajo la escala de: 0.00 a 0.20 (muy baja), 0.21 a 0.40 (baja), 0.41 a 0.60 (media), 0.61 a 0.80 (alta), y 0.81 a 1.00 (muy alta).

\subsection{Procedimiento metodológico}

El análisis de la información se basa en un enfoque cuantitativo derivado de la aplicación de la técnica estadística de regresión, para obtener la asociación existente entre las variables, donde $Y$ es el desarrollo sustentable (IDS) y $X i$ es la construcción de vivienda (ICV). Este análisis desarrolla un modelo matemático que expresa la relación entre dos variables y estima el valor de la variable dependiente. La ecuación [1] de la forma general de la regresión lineal es:

$$
Y^{\prime}=a+b X i
$$

donde $Y$ ' es el valor predictivo de la variable $Y$ para un valor $X i$ seleccionado; $a$ es la intersección de la línea recta con el eje $Y$; $b$ es la pendiente de la línea recta, o el cambio promedio en $Y$ ' por cada cambio en una unidad (ya sea aumentando o disminuyendo) de la variable independiente $X i$; Xi es el valor que se elige para la variable independiente. A los valores $a$ y $b$ de la ecuación de regresión se les conoce como coeficientes de regresión.

Para validar los resultados de la regresión y comprobar las hipótesis se toma como referencia el valor del coeficiente de correlación derivado de la regresión entre el valor del índice de desarrollo sustentable (IDS) y el índice de construcción de vivienda (ICV) de las ciudades durante 2000-2015. La correlación será válida si

$$
\text { Corr }(\text { IDS-ICV) }>0.60
$$

y que además posea una significancia $\geq 90 \%$. La correlación obtenida, en sentido positivo o negativo, se evaluará con la escala: 0.00 a 0.20 (muy baja), 0.21 a 0.40 (baja), 0.41 a 0.60 (media), 0.61 a 0.80 (alta); y 0.81 a 1.00 (muy alta). 


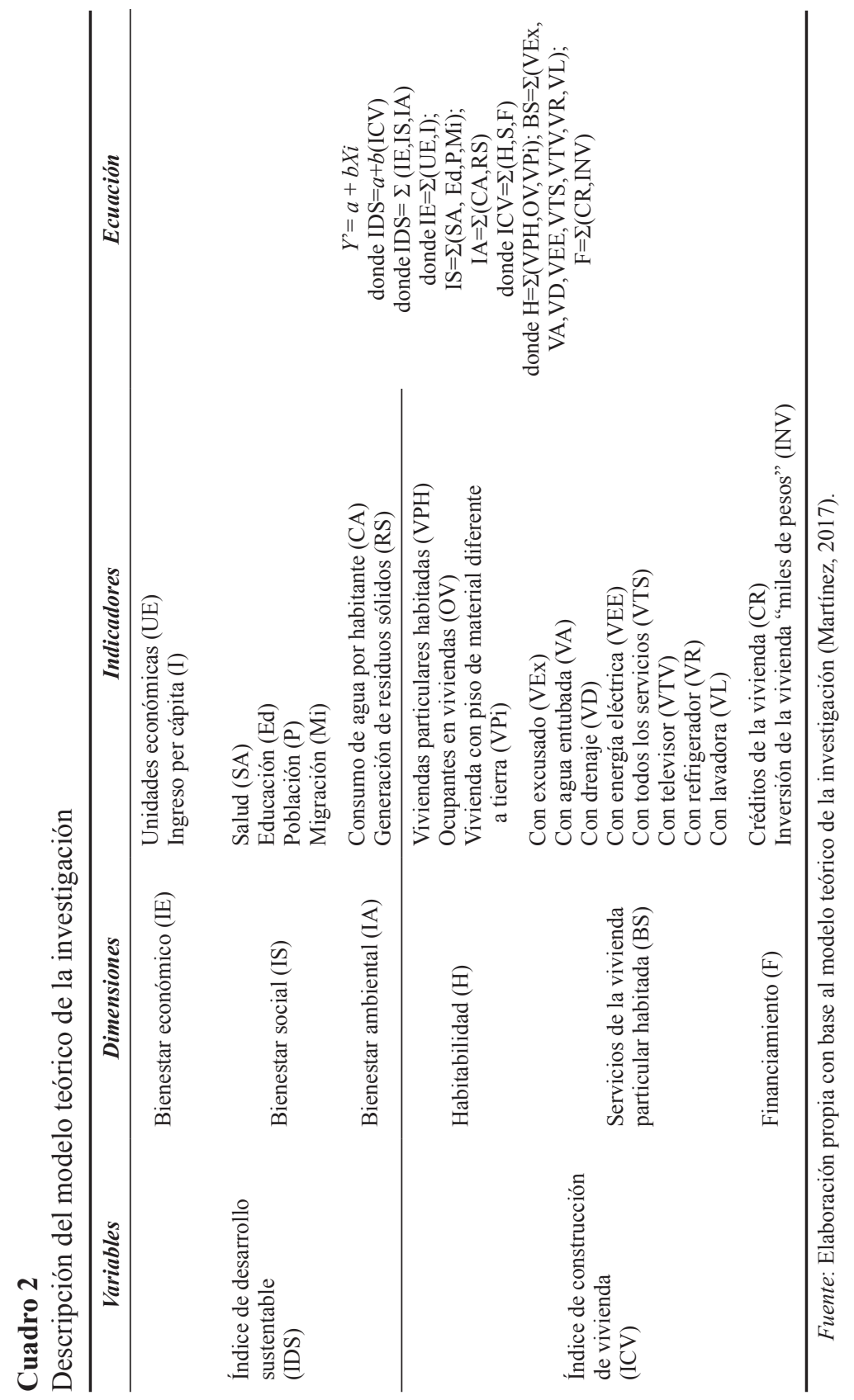


Por otra parte, si las ciudades se consideran nodos de una red, entonces, dado un nodo de una red $G=(V, E)$, donde $V$ es su conjunto de vértices ( $v)$ y $E$ su conjunto de aristas, la centralidad de grado $(C)$ se define como:

$$
C(v)=\operatorname{grado}(v)
$$

siendo la centralidad la medida que corresponde al número de enlaces $(r)$ que posee un nodo con respecto a los demás. Si para cada nodo $(v \in V)$ se tiene la matriz de adyacencia, entonces la centralidad de grado de cada nodo $j$ se puede definir como:

$$
\left.C(j)=\sum r_{i j}=\sum\{\text { Corr (IDS-ICV) })_{i j} / d_{i j}{ }^{2}\right\}
$$

donde $d_{i j}$ es la distancia entre los nodos (ciudades), operando las correlaciones existentes entre los nodos como elementos de un modelo gravitacional. Existen medidas de centralidad correspondientes al grado de entrada $C_{I}(j)$ o de salida $C_{2}(j)$. En el sentido de interacción entre ciudades, el primero puede interpretarse como una medida de flujos de ingreso (de mercancías, personas, vehículos, etc.), mientras que el segundo como una de salida (también de mercancías, personas, vehículos, etc.). Los criterios que normalizan esta medida son: dividir el grado de cada nodo por el máximo grado obtenido de la red, o bien dividirlo por el número total de nodos de la red. El modelo teórico de redes de ciudades del artículo propone que:

$$
C(j)=\sum r_{i j}=1 / 2\left[\left|C_{1}(j)\right|+\left|C_{2}(j)\right|\right]
$$

es decir, la red de asociaciones de las ciudades depende de la media de la centralidad de salida y de entrada, que a su vez dependen de las correlaciones existentes entre las ciudades (en valor absoluto), generando una jerarquía entre ellas.

La magnitud de la centralidad puede evaluarse, en porcentaje, por la escala: 0 a 20 (muy baja: no existen lugares centrales en la red), 21 a 40 (baja: se empiezan a conformar los lugares centrales en la red), 41 a 60 (media: existen lugares centrales equilibrados), 61 a 80 (alta: existen lugares centrales que inician el desequilibrio en la red, por lo que uno, o más, tiende a convertirse en dominante); y 81 a 100 (muy alta: existen lugares centrales dominantes -a veces uno solo- que centraliza totalmente el control de la red). Para la construcción de las redes se utiliza la aplicación del programa Ucinet 6 for Windows, versión 6.572 . 


\section{Resultados}

\subsection{El contexto del desarrollo de la red de ciudades de Oaxaca}

El estado de Oaxaca se compone de 570 municipios. Se localiza en el sur de México, y su capital se ubica en las coordenadas $17^{\circ} 0^{\prime}$ latitud Norte, $96^{\circ}$ 47' longitud Oeste, a una altitud de 1560 metros sobre el nivel del mar. En el presente artículo se consideran catorce ciudades con población mayor a 15000 habitantes, indicadas en el Mapa 2. Una característica particular de Oaxaca es que es la entidad que posee la mayor diversidad biocultural de México y muestra una correlación estrecha con la complejidad ecológica del territorio. Como ejemplo de su biodiversidad, Oaxaca tiene registradas más de 600 especies de vertebrados, de las cuales 95 son endémicas de esta entidad (De Ávila, 2008: 565-573).

Las ciudades analizadas se denominan "red de las ciudades de Oaxaca" (RCoax); en el Cuadro 3 se indica su nombre oficial y el nombre cotidiano; este último es el que se utilizará a lo largo del texto, con la excepción de la Zona Metropolitana de Tehuantepec y la Zona Metropolitana de Oaxaca, que se denominarán con las abreviaturas ZMT y ZMO.

\section{Cuadro 3}

Ciudades de Oaxaca, México

\begin{tabular}{ll}
\hline Nombre oficial & Nombre cotidiano \\
\hline Ciudad Ixtepec & Ixtepec \\
Heroica Ciudad de Huajuapan de León & Huajuapan \\
Heroica Ciudad de Juchitán de Zaragoza & Juchitán \\
Loma Bonita & Loma Bonita \\
Matías Romero Avendaño & Matías Romero \\
Miahuatlán de Porfirio Díaz & Miahuatlán \\
Ocotlán de Morelos & Ocotlán \\
San Juan Bautista Tuxtepec & Tuxtepec \\
San Pedro Mixtepec, Dto. 22 & Puerto Escondido \\
Heroica Ciudad de Tlaxiaco & Tlaxiaco \\
Crucecita, Santa María Huatulco & Huatulco \\
Santiago Pinotepa Nacional & Pinotepa Nacional \\
Zona Metropolitana de Tehuantepec & Zona Metropolitana de Tehuantepec (ZMT) \\
Zona Metropolitana de Oaxaca & Zona Metropolitana de Oaxaca (ZMO) \\
\hline
\end{tabular}

Fuente: Elaboración propia con base al Sistema de Información Municipal (CIEDD, 2014). 


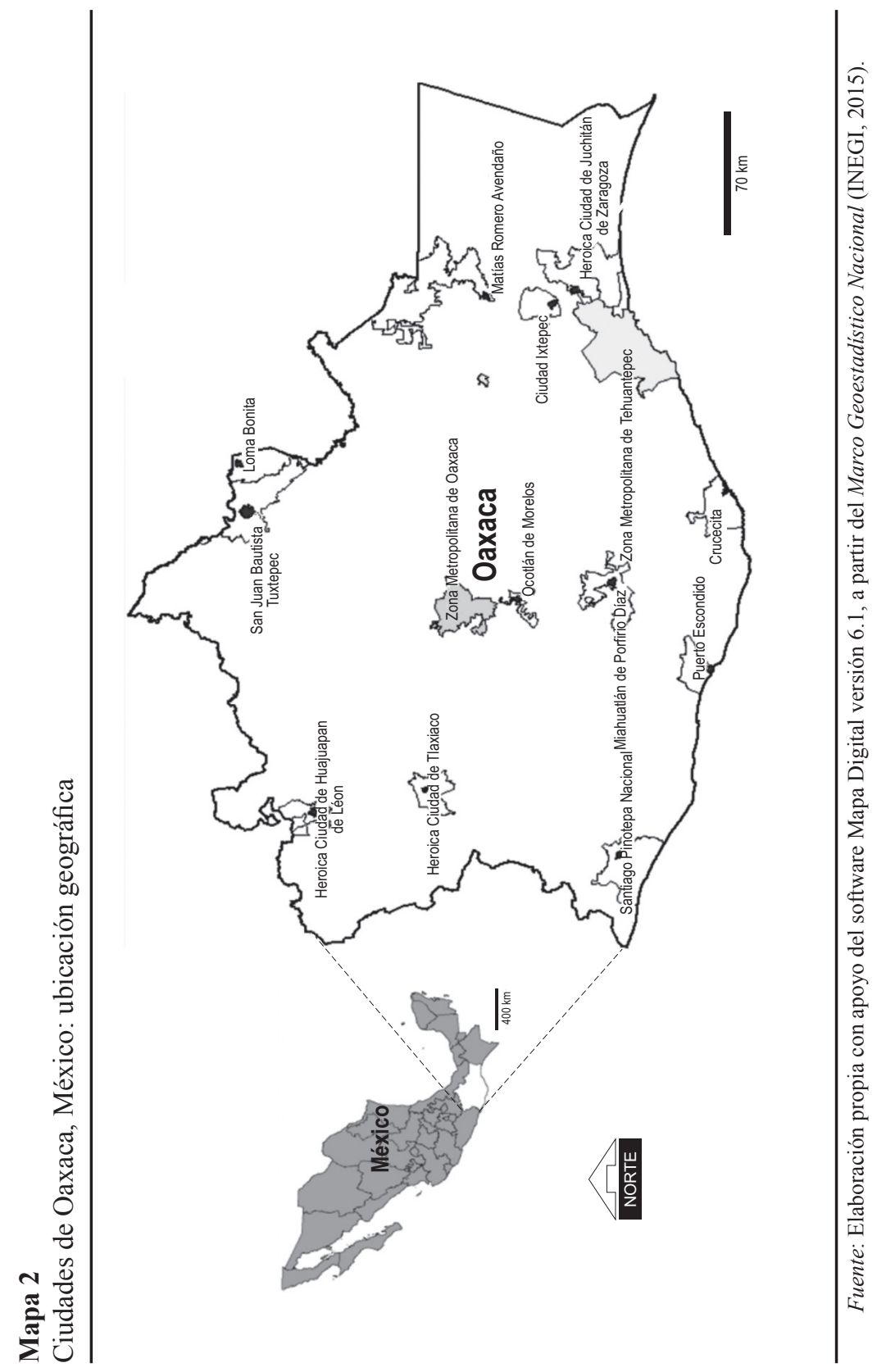


En la RCoax una proporción alta de población se concentra en localidades urbanas: $55.7 \%$ de sus habitantes vive en alguna ciudad y la tendencia es incrementar los espacios urbanos. Demográficamente la RCoax es muy desigual, pues fuera de los 14 centros urbanos con más de 15000 habitantes, considerados ciudades, predominan las pequeñas localidades. De estas ciudades sólo destaca la ZMO a nivel nacional con una jerarquía intermedia.

Oaxaca ocupa el segundo lugar en México con mayor población rural. De acuerdo con los datos censales del INEGI (2010), el 44.3\% de la población vive en localidades rurales. En la entidad se tienen registradas más de 10000 localidades rurales (con menos de 2500 habitantes cada una) y 156 localidades mixtas (rurales-urbanas de 2500 a 14999 habitantes). La dispersión de las localidades es influida por la accidentada orografía, la difícil accesibilidad y los patrones históricos de ocupación territorial por parte de la población. En cuanto a la urbanización del estado, más del $80 \%$ de sus 570 municipios se ubica en un rango de urbanización muy bajo, y menos del $15 \%$ entre alto y muy alto. Esto produce marginación y aislamiento, y refleja un grado de desarrollo por debajo de la media nacional, con niveles de productividad que no corresponden a los exigidos por la actividad económica actual. Además, la orografía hace costosa la cobertura de infraestructura económica y social hacia las poblaciones más aisladas y con reducido número de habitantes.

En la distribución regional de las ciudades encontramos interacciones poco consistentes, ya que existen regiones del estado como la Mixteca, la Cañada, la Sierra Sur o la Sierra Norte, donde no se detecta ninguna ciudad de jerarquía importante. Sólo las regiones de los Valles Centrales y el Istmo cuentan con un sistema de ciudades articuladas. En la región Costa las ciudades ya presentan cierta articulación, pero básicamente con la ciudad capital, la ZMO. Como consecuencia, las ciudades de Oaxaca se comportan como un sistema disperso de lugares centrales, que manifiesta baja interacción entre urbes y concentración del ingreso entre y en el interior de éstas (Miguel, 2004). En la actualidad, es la concentración territorial la que muestra mayor influencia en la estructuración de la RCoax, la cual cuenta con tres ciudades que poseen más de 100000 habitantes: Tuxtepec, ZMT y la ZMO (esta última posee la mayor población del sistema). Dos ciudades, Juchitán y Huajuapan, cuentan con más de 50000 habitantes; las nueve restantes poseen al menos 15000 habitantes (Conapo, 2014a).

Con base en los censos y conteos de población y vivienda del periodo 2000-2015 (INEGI, 2000; 2005; 2010; 2015), en lo que respecta al incremento de la población, cuatro ciudades (Miahuatlán, Puerto Escondido, 
Tlaxiaco y Huajuapan) poseen tasas superiores al 2\%. Matías Romero es la única que manifestó una tasa de crecimiento poblacional negativa $(-0.53 \%)$. Tres urbes poseen un PIB per cápita por arriba de los 15000 dólares anuales (en orden descendente: Huajuapan, Tlaxiaco e Ixtepec). Los habitantes de siete ciudades ganan menos de esta cantidad, pero más de 10000 (ZMO, Tuxtepec, Huatulco, Loma Bonita, Ocotlán, Matías Romero y la ZMT). El resto de las 14 ciudades posee un ingreso menor. Asociado con lo señalado, con un alto grado de marginación destacan las ciudades de Miahuatlán y Ocotlán. En la ZMO el 9.72\% de su población presenta un grado de marginación alto, mientras que para la ZMT corresponde al $20 \%$ de su población. Las ciudades con grado de marginación medio son: Juchitán, Loma Bonita, Matías Romero, Tlaxiaco y Huatulco. El $22.37 \%$ de la población de la ZMO y el $26 \%$ de la ZMT presentan grado medio de marginación.

Todas las ciudades de la RCoax poseen un índice de desarrollo humano (IDH) alto. Específicamente, para 2010 el IDH en las ciudades de Oaxaca fue superior a 0.80 , excepto para Miahuatlán (0.79) y Pinotepa Nacional. La $\mathrm{ZMO}$, con un IDH de 0.90, presenta el mayor valor de este indicador. En 2015 los valores del IDH en la RCoax indican crecimiento ascendente, excepto para Ixtepec.

Por estrato urbano se observa mayor crecimiento para las ciudades entre 50000 a 100000 habitantes (con un IDH promedio de 0.84 ) y la ZMO aparece con un crecimiento de $0.61 \%$. Comparando la tasa de la población con el crecimiento del desarrollo, sólo Loma Bonita poseía una expansión de su desarrollo (con un valor de $0.60 \%$ superior al de la población). En todas las ciudades el nivel general del IDH presenta estabilidad, pero en 13 urbes su desarrollo mantenía un crecimiento pobre, por lo cual urge detectar los factores que puedan contribuir a acelerarlo, como se supone contribuye la vivienda en el caso analizado.

El análisis del desarrollo sustentable en las ciudades de Oaxaca muestra un proceso con una tendencia al alza, pero con niveles que denotan un desarrollo bajo y medio (con valores de 0.52 a 0.67 en los años analizados). Con respecto a las ciudades, en la Gráfica 1 se observa que, en orden descendente, las ciudades con un nivel de desarrollo sustentable alto son: Ixtepec, Pinotepa Nacional, ZMO, Tuxtepec, Huatulco, Miahuatlán y Matías Romero. El resto de las ciudades se ubican en un nivel de desarrollo medio.

La Gráfica 2 muestra el comportamiento del desarrollo sustentable con respecto al incremento de la construcción de la vivienda. En esta interacción se observa una tendencia divergente entre ambos indicadores, y como ejemplo se muestra que en el año 2012 se obtuvo el valor más alto en el índice 


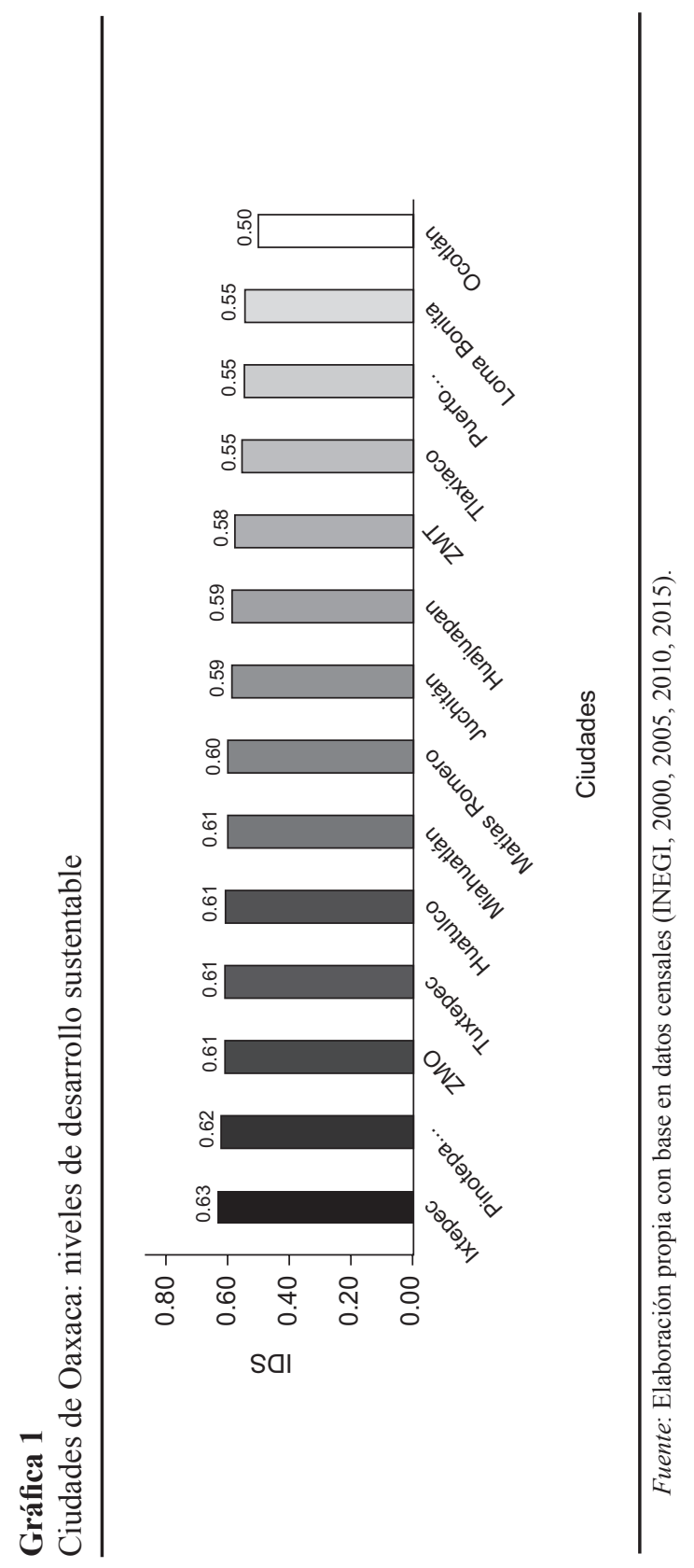




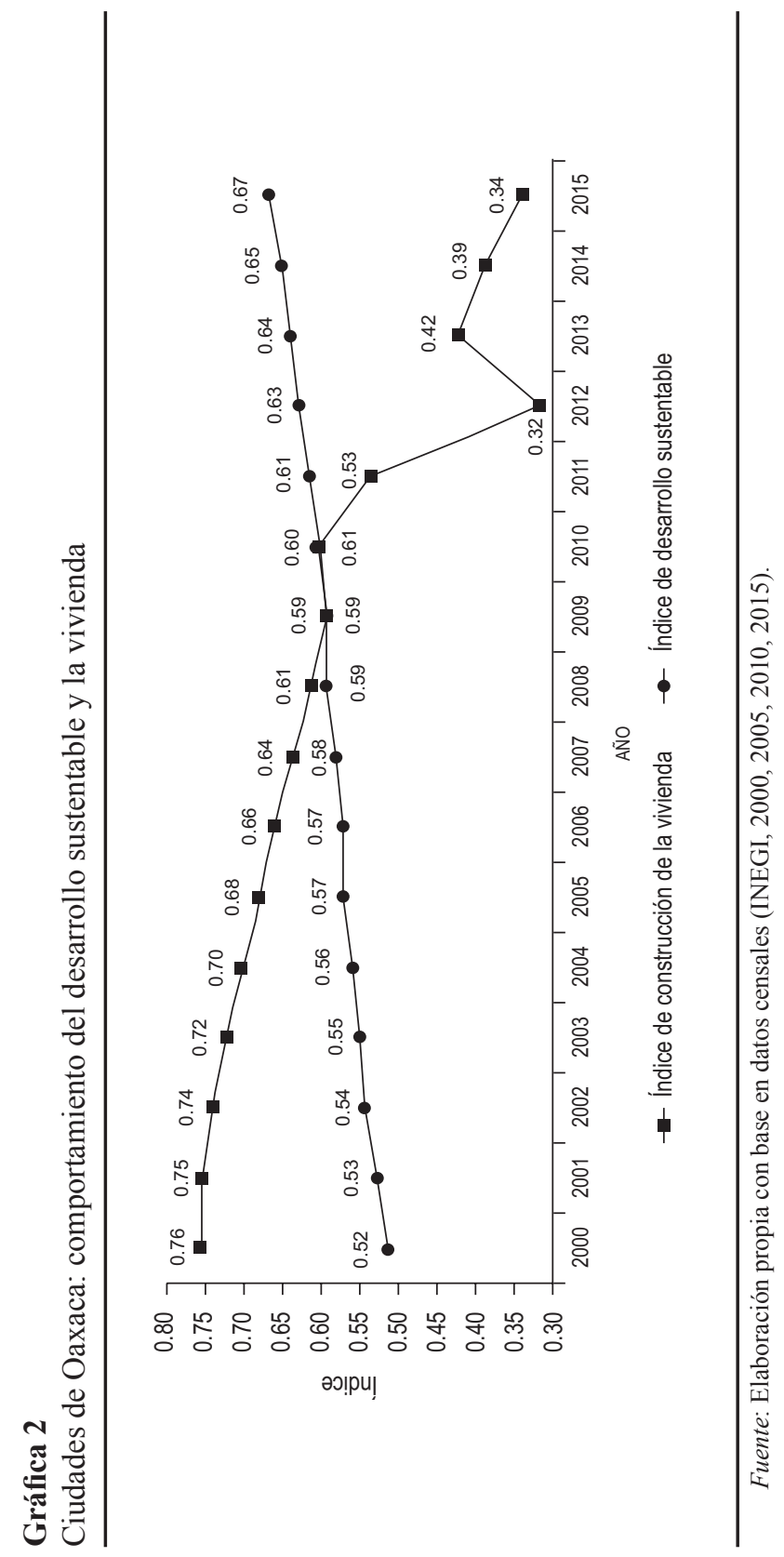


de construcción de la vivienda, en tanto que el índice de desarrollo sustentable iba a la baja. La correlación entre ambos valores es de -0.92, indicando una alta asociación negativa entre ambos índices.

\subsection{La vivienda en las ciudades de Oaxaca}

De acuerdo con el Censo de Población y Vivienda 2010 (INEGI, 2010), en México habitaban 112336538 personas en 28607568 viviendas, con un promedio de 3.9 ocupantes por vivienda. Se proyecta que para el año 2050 la población de México será de 122 millones de habitantes (Conapo, 2014b), y ya en la tercera década de este siglo este país tendrá cerca de 50 millones de hogares aproximadamente. Se estima que para satisfacer sus necesidades será necesaria la construcción de casi 11 millones de viviendas nuevas entre 2011 y 2030, y que unos 9 millones de viviendas requerirán renovación parcial o total en el mismo periodo. Este crecimiento significativo de la población y del número de hogares permite identificar grandes retos para el abastecimiento de vivienda, energía y agua en el país.

Por tal motivo, el sector de la vivienda es un foco permanente de atención para la sociedad en general. Su crecimiento genera un aumento en la demanda de suministro de servicios públicos (agua potable, energía eléctrica y drenaje) para satisfacer las necesidades básicas de la población, así como del crecimiento económico, por tanto, a medida que la población crece existe mayor explotación de los recursos naturales, así como de energéticos. La Sociedad Hipotecaria Federal consideró que durante 2015 fueron adquiridas 15013 viviendas en el estado de Oaxaca, lo que correspondió al 2.44\% del total nacional; y según la clasificación para las viviendas del registro único de vivienda (RUV), ${ }^{1}$ en Oaxaca el tipo de vivienda que destacó fue la tradicional o popular tipo B3 $\left(76.2 \mathrm{~m}^{2}\right)$ (SHF, 2015: 68).

Durante el periodo 2000-2010 Tlaxiaco tuvo el mayor crecimiento anual del total de viviendas (10.62\%), y con el menor resultó Matías Romero con $2.68 \%$. Por estrato, el mayor crecimiento lo tuvieron las ciudades pequeñas con $6.91 \%$ de crecimiento anual. Por su tasa de crecimiento (TC) durante 2010-2015 destaca Tlaxiaco con el mayor aumento (8.83\%), y con el menor crecimiento Matías Romero (2.76\%). El 40.65\% de las viviendas particulares utiliza como combustible quemar leña o carbón sin chimenea, lo cual

1 Según la clasificación para las viviendas del registro único de vivienda (RUV): vivienda económica (45.5 $\mathrm{m}^{2}$ de superficie construida), vivienda popular tipo B.1 $\left(48.1 \mathrm{~m}^{2}\right)$, vivienda popular tipo B.2 $\left(49.6 \mathrm{~m}^{2}\right)$, vivienda popular tipo B3 $\left(76.2 \mathrm{~m}^{2}\right)$, vivienda media $\left(107.9 \mathrm{~m}^{2}\right)$ y vivienda residencial $\left(178.3 \mathrm{~m}^{2}\right)$. 
tiene un impacto negativo en el medio ambiente e incrementa la susceptibilidad a padecer enfermedades de las vías respiratorias (Moy, 2016).

El crecimiento de la vivienda ha aumentado anualmente en Oaxaca, ya que registra un total de 1518989 viviendas (INEGI, 2015), de las cuales solamente $65.25 \%$ cuenta con electricidad, $58.74 \%$ con agua, $51.03 \%$ con drenaje, y 33.20\% tiene todos los servicios (Gráfica 3).

Con respecto a los servicios, y de acuerdo con su tasa de crecimiento, en las viviendas de la RCoax hay mayor equipamiento de electricidad y agua en Huatulco, y mejor disponibilidad del servicio de drenaje en Miahuatlán, como se aprecia en la Gráfica 4.

En el 2010, según el número de viviendas habitadas en la RCoax, destaca la ZMO con 194393 viviendas; Ocotlán fue la ciudad con menor número, con 4431 viviendas.

Con respecto al promedio de habitantes por vivienda, en el año 2000 fue de 4.49 y en 2015 se redujo a 3.68 habs./viv., es decir, hubo una reducción del hacinamiento. Tal promedio es muy similar entre las ciudades oaxaqueñas; en el año 2015 en la RCoax destaca Miahuatlán, con 3.96 habs./viv., y Loma Bonita, con el menor promedio, de 3.38 habs./viv.

Por el número de viviendas habitadas con servicio de energía eléctrica destaca la ZMO con 170798 viviendas, contando con el $17.23 \%$ del total de viviendas a nivel estatal; Ocotlán fue la ciudad con menor número de ellas

\section{Gráfica 3}

Estado de Oaxaca: porcentaje de viviendas con servicios, 2015

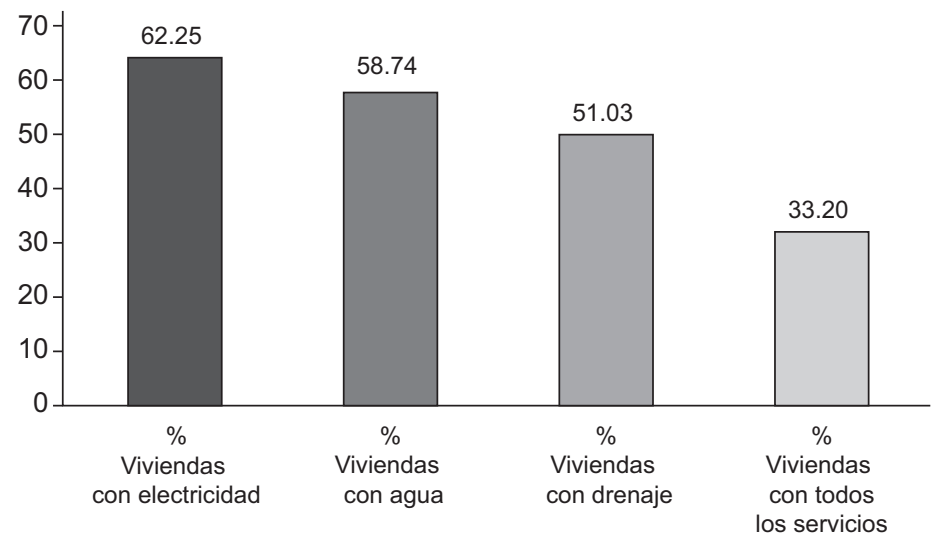

Fuente: Elaboración propia con base en datos censales (INEGI, 2000, 2005, 2010 y 2015). 


\section{Gráfica 4}

Ciudades de Oaxaca: servicios en viviendas
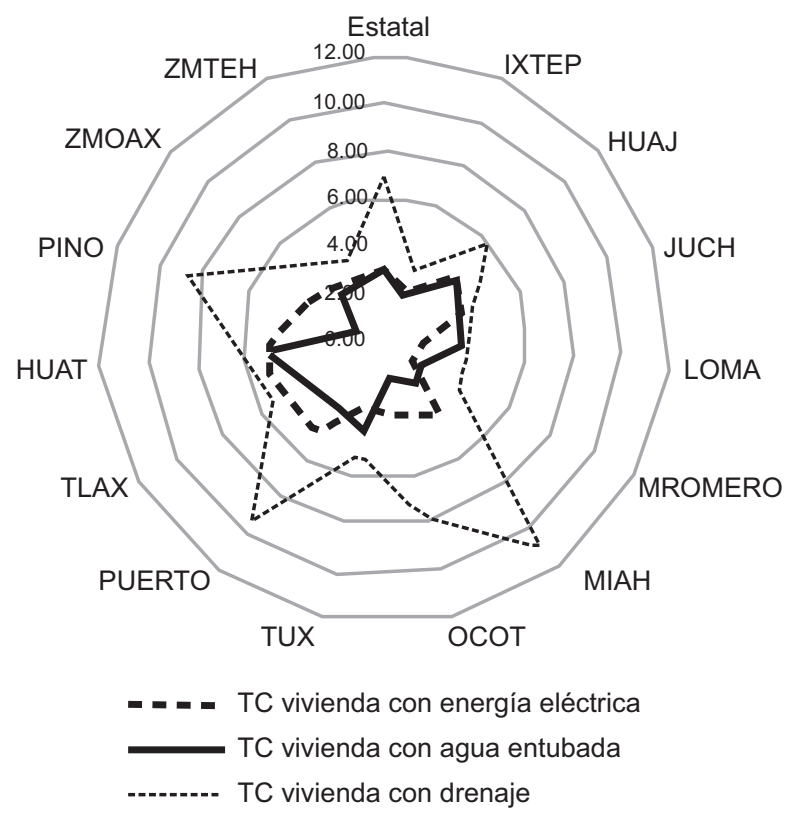

TC: Tasa de crecimiento

Fuente: Elaboración propia con base en datos censales (INEGI, 2000, 2005, 2010 y 2015).

(con 5291 viviendas, el $0.53 \%$ del total de viviendas para el año 2015). En cuanto al crecimiento de las viviendas habitadas con servicio de energía eléctrica, durante 2000-2015 Huatulco tuvo el mayor crecimiento anual (5.14\%) y Matías Romero el menor, con 1.07 por ciento.

Por el número de viviendas habitadas con servicio de agua entubada destaca la ZMO con 153624 viviendas, contando con el 17.22\% del total de viviendas a nivel estatal; Ocotlán fue la ciudad con menor número de ellas (con 3951 viviendas, el 0.44\% del total durante 2015). En el crecimiento de las viviendas habitadas con servicio de agua entubada se observa que Huatulco tuvo el mayor crecimiento (4.91\%) y Pinotepa Nacional el menor, con $1.33 \%$ durante $2000-2015$.

Por el número de viviendas habitadas con servicio de drenaje destaca la ZMO con 159354 viviendas, contando con el 20.56\% del total a nivel estatal; Ocotlán fue la ciudad con menor número de ellas (con 3862 viviendas, 
el $0.50 \%$ del total de viviendas para el año 2015). En el crecimiento de las viviendas habitadas con servicio de drenaje durante 2000-2015 se observa que Miahuatlán tuvo el mayor crecimiento anual (11.07\%), e Ixtepec el menor, con 2.88 por ciento.

Por último, por el número de viviendas habitadas con todos los servicios (energía eléctrica, agua entubada y drenaje) destaca la ZMO con 137756 viviendas, contando con el $20.32 \%$ del total a nivel estatal; Ocotlán fue la ciudad con menor número de ellas (con 2439 viviendas, el $0.36 \%$ del total de viviendas para el año 2015). En el crecimiento de las viviendas habitadas con todos los servicios, se observa que durante 2000-2015 Puerto Escondido tuvo el mayor crecimiento anual (11.27\%), e Ixtepec el menor, con 3.74 por ciento.

Aunque las correlaciones entre las ciudades a partir de los indicadores de la vivienda y el desarrollo sustentable muestran valores altos (con promedios superiores a 0.9), lo que indica una fuerte interacción entre las ciudades (Cuadro 4), que también se refleja en la alta densidad de la red $(100 \%)$, el análisis de redes arroja que en lo que respecta a la centralidad, el valor promedio de este indicador de la RCoax es $0.20 \%$, manifestando una muy baja centralidad del conjunto; lo que significa que no existen lugares centrales derivados de la actividad analizada, y que a pesar de las altas correlaciones entre las ciudades, existe dispersión derivada de la actividad de la construcción de la vivienda.

En el Cuadro 5 se muestran, de manera descendente, los niveles de centralidad, así como la centralidad del conjunto y la densidad de la red en valor absoluto de cada ciudad considerada en el presente análisis.

\section{Resultados, discusión y conclusiones}

En este artículo la hipótesis 1 evalúa el grado de asociación de la creación de viviendas y el desarrollo sustentable. En el Esquema 2 se muestran los resultados obtenidos.

La hipótesis propuesta de que la construcción de vivienda estimula el desarrollo sustentable se rechaza debido a que existe una asociación alta significativa negativa entre el desarrollo sustentable y la creación de la vivienda en las ciudades de Oaxaca (coef. corr. -0.92; sig. 0.001); es decir, la vivienda construida no contribuye con la sustentabilidad de la red de las ciudades de Oaxaca, sino que por el contrario, la afecta negativamente. La relación detallada entre la vivienda y el desarrollo se indica en el Cuadro 6.

En lo que respecta a la hipótesis 2, que propone que existen ciudades que ejercen la función de "lugares centrales" derivados de la actividad de la 


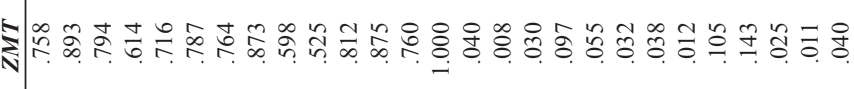

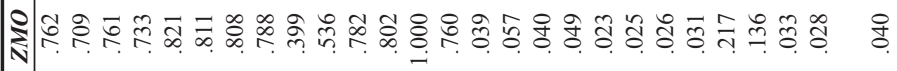

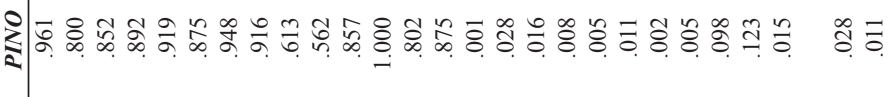

군

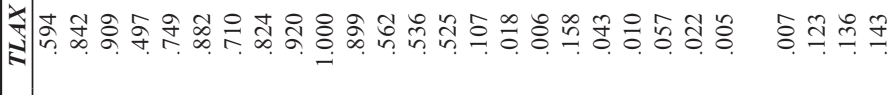

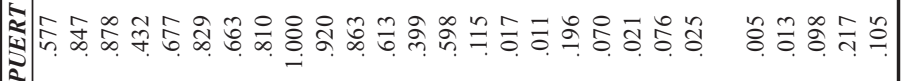

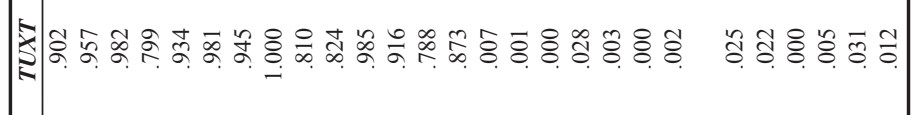

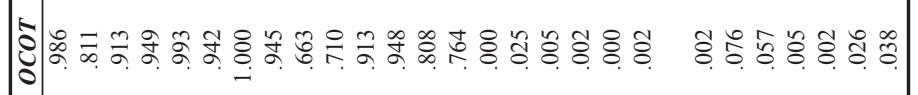

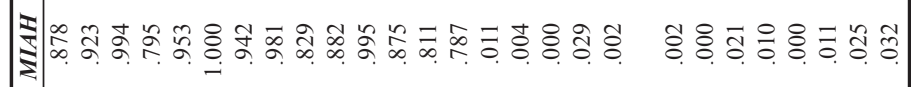

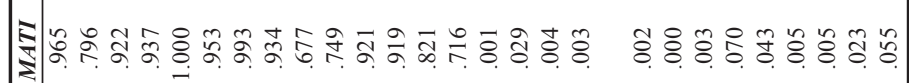

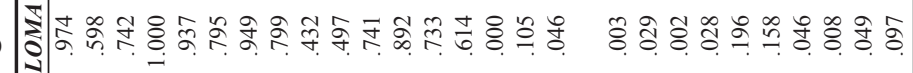

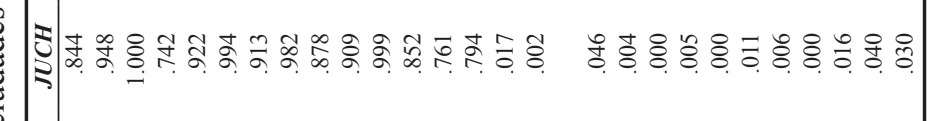

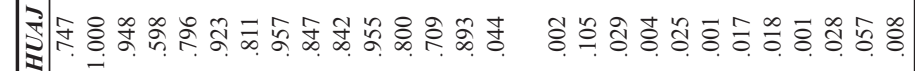

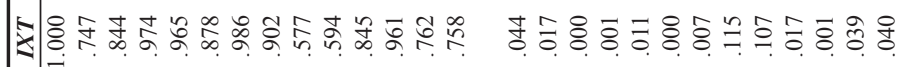

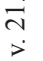




\section{Cuadro 5}

Centralidad de las ciudades de Oaxaca

\begin{tabular}{lccc}
\hline & \multicolumn{3}{c}{ Centralidad } \\
\cline { 2 - 4 } Ciudad & $\begin{array}{c}\text { Salida } \\
\text { (decimales) }\end{array}$ & $\begin{array}{c}\text { Entrada } \\
\text { (decimales) }\end{array}$ & $\begin{array}{c}\text { Promedio } \\
\text { (\%) }\end{array}$ \\
\hline Juchitán & 0.004 & 0.004 & 0.4 \\
Ixtepec & 0.003 & 0.003 & 0.3 \\
ZMT & 0.002 & 0.002 & 0.2 \\
Ocotlán & 0.001 & 0.001 & 0.1 \\
ZMO & 0.001 & 0.001 & 0.1 \\
Tuxtepec & 0.001 & 0.001 & 0.1 \\
Loma Bonita & 0.001 & 0.001 & 0.1 \\
Matías Romero & 0.001 & 0.001 & 0.1 \\
Miahuatlán & 0.000 & 0.000 & 0.0 \\
Huatulco & 0.000 & 0.000 & 0.0 \\
Puerto Escondido & 0.000 & 0.000 & 0.0 \\
Tlaxiaco & 0.000 & 0.000 & 0.0 \\
Huajuapan & 0.000 & 0.000 & 0.0 \\
Pinotepa Nacional & 0.000 & 0.000 & 0.0 \\
Centralidad del conjunto & $9.470 \%$ & & \\
Densidad de la red (valor absoluto) & 1.00 & & \\
\hline
\end{tabular}

Fuente: Datos proporcionados por UCINET, elaboración con los datos censales (INEGI, 2000, 2005, 2010, 2015).

\section{Esquema 2}

Niveles de asociación entre los índices de construcción de vivienda y de desarrollo sustentable en las ciudades de Oaxaca

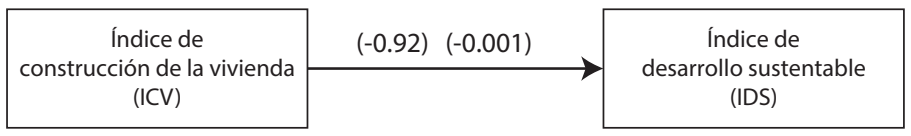

Fuente: Elaboración propia (coef. corr. 0.001; sig.-0.92). 


\section{Cuadro 6}

Ecuaciones de regresión de la vivienda y el desarrollo con las ciudades de Oaxaca

\begin{tabular}{lc}
\hline Concepto & Ecuación IDS: desarrollo sustentable \\
\hline IDS: índice de desarrollo sustentable & IDS $=0.847+0.01145 \mathrm{ICV}$ \\
ICV: índice de construcción de vivienda & \\
\hline
\end{tabular}

Fuente: Elaboración propia con base al programa estadístico IBM SPSS Statistics, v. 21.

vivienda en Oaxaca, específicamente se esperaría que las urbes de mayor tamaño en cuanto a población y territorio, como son las zonas metropolitanas (ZMO y ZMT), cumplieran esta función; se comprueba en el análisis de redes que esto no está ocurriendo en la RCoax, por lo cual puede concluirse que el desarrollo sustentable no es activado por la construcción de viviendas en su territorio, por lo que no se promueven lugares centrales derivados de esta actividad.

Como ya se señaló, la centralidad de las ciudades de Oaxaca muestra un promedio del $0.20 \%$, situándose tres ciudades con los mayores valores: Juchitán, Ixtepec y la ZMT. Otras urbes muestran una centralidad incipiente (Ocotlán, ZMO, Tuxtepec, Loma Bonita y Matías Romero), y el resto una centralidad nula. La centralidad de cada una de las ciudades de Oaxaca confirma que no existe un lugar central dominante, sino que hay una red con múltiples interacciones, en la cual ninguna domina la centralidad del conjunto, lo que denota un sistema de ciudades aisladas, pero con una posibilidad incipiente de que las urbes de Juchitán, Ixtepec y la ZMT puedan llegar a configurar una interacción más intensa y generar una red futura entre ellas (Figura 2).

En conclusión, la construcción de viviendas no está contribuyendo al desarrollo sustentable de las ciudades de Oaxaca, y territorialmente influye en la dispersión. Por consiguiente, se requieren políticas públicas que faciliten la edificación de viviendas con la intención de mejorar la centralidad de la red de ciudades, de preferencia viviendas con diseños urbanísticos integrados territorialmente a las ciudades existentes y que cuenten con todos los servicios, para generar un mayor impacto en el bienestar económico, el social y el ambiental, y de esta forma contribuir a mejorar la calidad de vida de la población de los centros urbanos de dicha entidad de México. 


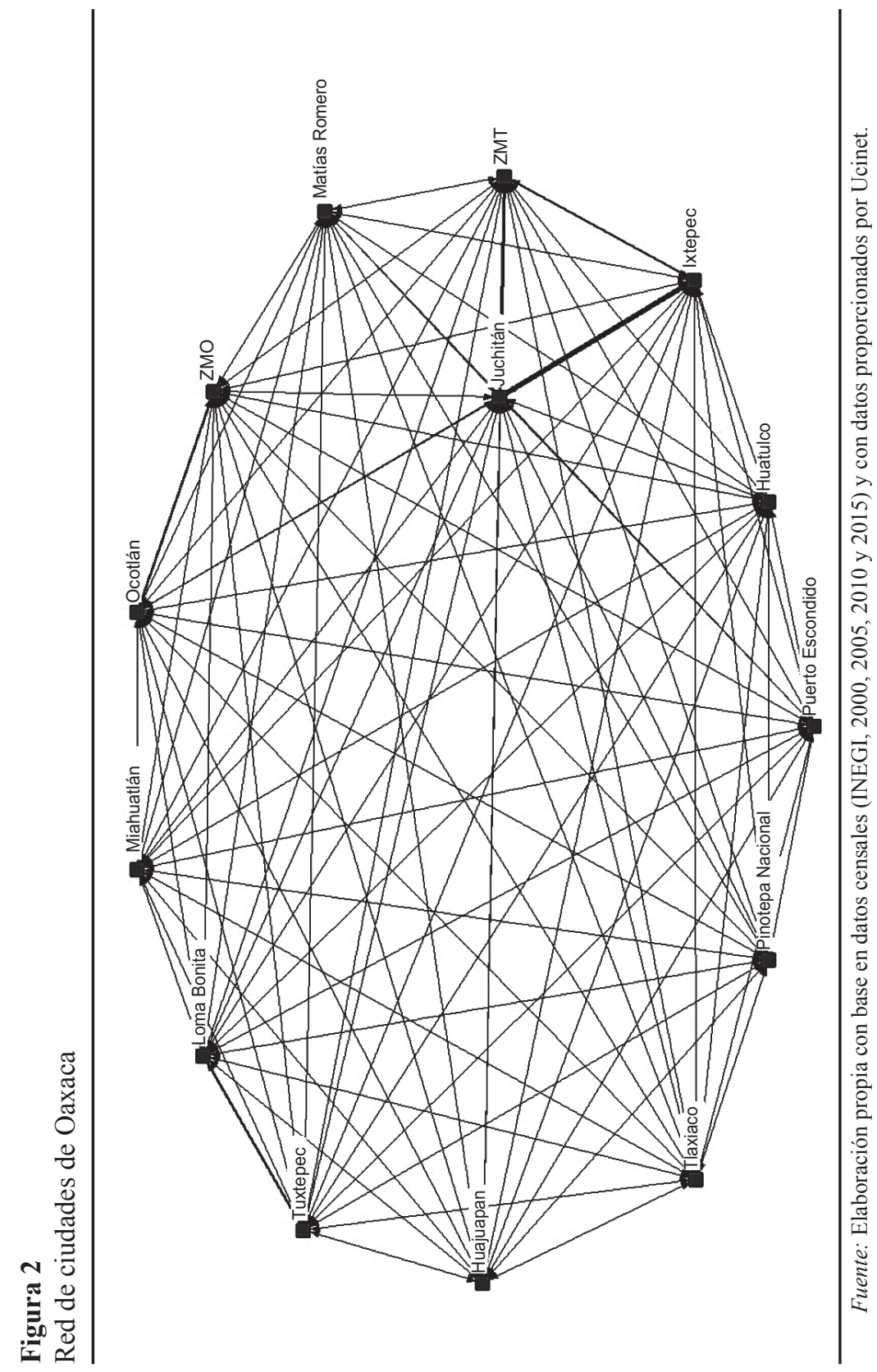




\section{Bibliografía}

Casado, G.I. (2010), “Apuntes sobre el origen y la historia de la ciudad”, Contribuciones a las ciencias sociales, Eumednet. Recuperado de http://www.eumed. net/rev/cccss/07/icg2.htm (10 de enero de 2015).

CEDRUS (2016), "Vivienda", Documento de Investigación, México, Facultad de Economía, UNAM. Disponible en: http://www.economia.unam.mx/cedrus/ investigacion/propuestas-politica/vivienda.html (24 de octubre de 2016).

CIEDD (2014), Sistema de Información Municipal. Censos económicos, Oaxaca, Gobierno del estado de Oaxaca, Centro de Información Estadística y Documental para el Desarrollo. Disponible en: http://www.sim.oaxaca.gob.mx/ (25 de mayo de 2014).

Clavel, M. (2002), Sociologie de l'urbain, París, Anthropos.

Conapo (1991), Sistema de ciudades y distribución espacial de la población, tomo I, México, Consejo Nacional de Población.

Conapo (2014a), Índice de marginación por localidad 2010, con base en el Censo de Población y Vivienda 2010 del INEGI, México, Consejo Nacional de Población.

Conapo (2014b), Proyecciones de la población 2010-2050, México, Consejo Nacional de Población. Disponible en: http://www.conapo.gob.mx/es/CONAPO/ Proyecciones

Cori, B. (1995), "Urban networks", Geo-Italy, vol. 2, Bolonia, Pàtron, pp. 13-19.

De Ávila Blomberg, A. (2008), "Diversidad cultural y diversidad biológica en Oaxaca", documento, Oaxaca, Jardín Etnobotánico.

Ferrão, J. (1998), "Red urbana, instrumento de equidad, cohesión y desarrollo", Eure, vol. 24, núm. 71. Disponible en: http://www.redalyc.org/articulo.oa?id=19607105 (26 de enero de 2017).

Galán, J.L., C. Casanueva e I. Castro-Abancéns (2010), “Las relaciones empresariales: una tipología de redes”, Innovar, vol. 20, núm. 38, pp. 27-44. Disponible en: http://idus.us.es/xmlui/handle/11441/49637 (26 de enero de 2017).

Gobierno de Oaxaca (2012), Volumen de residuos sólidos urbanos, Oaxaca, Gobierno del Estado de Oaxaca, Instituto Estatal de Ecología y Desarrollo Sustentable.

Hernández, V.L. (2016), "Análisis de la centralidad y el desarrollo sustentable en la microrregión zapoteca Sierra Sur”, tesis de maestría en Ciencias, Desarrollo Regional y Tenológico, Oaxaca, Instituto Tecnológico de Oaxaca.

INEGI (2000), Censo General de Población y Vivienda 2000. Principales resultados por localidad. Sistema de Integración Territorial, ITER 2000, México, Instituto Nacional de Estadística y Geografía. Disponible en: http://www.inegi.org. $\mathrm{mx} /$ sistemas/consulta_resultados/iter2000.aspx?c=27437\&s=est (27 de septiembre de 2015).

INEGI (2005), Conteo de Población y Vivienda 2005. Principales resultados por localidad. Sistema de Integración Territorial, ITER 2005, México, Instituto Nacional de Estadística y Geografía. Disponible en: http://www.inegi.org.mx/ 
est/contenidos/proyectos/ccpv/cpv2005/Pub_Y_Prod/default.aspx?t=16632 (27 de septiembre de 2015).

INEGI (2010), Censo de Población y Vivienda 2010. Tabulados básicos. Población total por municipio, sexo y grupos quinquenales de edad según tamaño de localidad, México, Instituto Nacional de Estadística y Geografía. Disponible en: http://www3.inegi.org.mx/sistemas/TabuladosBasicos/Default.aspx?c=27302 (27 de septiembre de 2015).

INEGI (2015), Marco geoestadístico nacional. Productos y servicios. Localidades, México, Instituto Nacional de Estadística y Geografía. Disponible en: http:// www.inegi.org.mx/geo/contenidos/geoestadistica/consulta_localidades.aspx (27 de septiembre de 2015).

Jayet, H., J.P. Puig y J.-F. Thisse (1996), "La décentralisation de l'action publique enjeux et problèmes", Revue d'Économie Politique, vol. 106, núm. 1 pp. 127158. Disponible en: http://www.jstor.org/stable/24700543

Lamy, B. (2006), "Sociología urbana o sociología de lo urbano", Estudios Demográficos y Urbanos, vol. 21, núm. 1 (61), pp. 211-225. Disponible en: http://estudios demograficosyurbanos.colmex.mx/index.php/edu/article/view/1267 (10 de junio 2015).

Martínez, K.A. (2017), "Análisis de la relación del desarrollo sustentable y la vivienda en las pequeñas, medianas y grandes ciudades de Oaxaca, durante 2000-2015", proyecto de tesis de maestría en Ciencias, Desarrollo Regional y Tecnológico, Oaxaca, Instituto Tecnológico de Oaxaca.

Miguel, A. (2004), Ciencia regional. Principios de economía y desarrollo, Oaxaca, Instituto Tecnológico de Oaxaca.

Miguel, A.E., J.C. Torres, P. Maldonado y N. Solís (2011), La teoría de la complejidad y el caos en la ciencia regional, Oaxaca, Instituto Tecnológico de Oaxaca.

Moy, Valeria (2016), "Los números fríos de Oaxaca", Nexos, México. Disponible en: www.nexos.com.mx/?p=28994 (1 agosto de 2016).

Nikos, A. (2005), "Teoría de la red urbana", Principles of Urban Structure, Design Science Planning, núm. 16. Disponible en: http://zeta.math.utsa.edu/ yxk833/ urbanweb-spanish.pdf (22 de Junio de 2012).

ONU (1996), Informe de la Conferencia de las Naciones Unidas sobre los Asentamientos Humanos (Habitat II), Estambul, Organización de las Naciones Unidas.

PNUD, México (2014), Índices de desarrollo humano: 2000, 2005 y 2010. Cálculos de la Oficina de Investigación en Desarrollo Humano (OIDH), México, PNUD México.

Rugiero, A.M. (2000), “Aspectos teóricos de la vivienda en relación al habitar", INVI, vol. 15. núm. 40. Disponible en: http://www.revistainvi.uchile.cl/index.php/ INVI/article/view/263

Sánchez, A. (2010), "Sistema de ciudades y redes de transporte en México", México, INEGI / Universidad Nacional Autónoma de México, Instituto de Investigaciones Económicas (inédito).

Sánchez, A. (2016), "Sistema de ciudades y redes urbanas en los modelos económi- 
cos de México", Problemas del Desarrollo. Revista Latinoamericana de Economía, vol. 47, núm. 184. Disponible en: http://www.redalyc.org/articulo. oa?id=11843154002 (26 de enero de 2017).

Schteingart, M. y M. Solís (1994), Vivienda y familia en México: un enfoque socioespacial, México, INEGI / El Colegio de México, A.C. / Universidad Nacional Autónoma de México, Instituto de Investigaciones Sociales.

Sedesol y UNAM (2000), Estrategia territorial nacional, México, Secretaría de Desarrollo Social / Universidad Nacional Autónoma de México, Instituto de Investigaciones Estéticas.

Serrano Martínez, J.M. (2000), "Redes urbanas y sistema de ciudades de Alemania. Algunas precisiones de cara al siglo XXI", Papeles de Geografía, núm. 31. Disponible en: http://www.redalyc.org/articulo.oa?id=40703108 (26 de enero de 2017).

SHF (2015), Estado actual de la vivienda en México 2015, México, Sociedad Hipotecaria Federal.

SIDESCA (2016), Sistema de Indicadores de Derechos Económicos, Sociales, Culturales y Ambientales, México, Observatorio de Política Social y Derechos Humanos. Disponible en: http://observatoriopoliticasocial.org/sidesc/ (18 de octubre de 2016).

Unikel, L., G. Garza y C. Ruiz (1978), El desarrollo urbano de México, México, El Colegio de México, A.C.

Unikel, L. y A. Necochea (1971), "Jerarquía y sistema de ciudades de en México", Demografía y Economía, vol. 5, núm. 1 (13), pp. 27-39. Disponible en: http:// estudiosdemograficosyurbanos.colmex.mx/index.php/edu/article/view/143/136

\section{Acerca de los autores}

Andrés Enrique Miguel-Velasco es doctor en Ciencias en Planificación de Empresas y Desarrollo Regional por el Instituto Tecnológico de Oaxaca. Actualmente es profesor investigador de la División de Estudios de Posgrado e Investigación en la misma institución. Su línea de investigación actual es el desarrollo regional sustentable. Entre sus últimas publicaciones destaca el artículo "El desarrollo sustentable y la centralidad de las localidades en una microrregión de pueblos originarios. El caso de la Sierra Sur de Oaxaca, México" (en coautoría con J.C. Torres, L. Hernández y R.M. Moncada), Delos: Desarrollo Local Sostenible, núm. 25, 2016. Disponible en http: // www.eumed.net/rev/delos/25/centralidad.html

Karina Aidee Martínez García es ingeniera industrial por el Instituto Tecnológico de Oaxaca, México. Actualmente es estudiante de la maestría en Ciencias en Desarrollo Regional y Tecnológico en la misma institución. Su 
línea de investigación actual es el desarrollo regional sustentable. Su tema de tesis para obtener el grado de maestría es el análisis de la relación del desarrollo sustentable y la vivienda en la red de las pequeñas, medianas y grandes ciudades de Oaxaca durante 2000-2015.

Maribel Pérez es maestra en Ciencias de la Educación por el Instituto de Estudios Universitarios, y cuenta con una especialidad en Competencias Docentes por la Universidad Pedagógica Nacional. Actualmente es estudiante del doctorado en Ciencias en Desarrollo Regional y Tecnológico en el Instituto Tecnológico de Oaxaca. Su línea de investigación actual es el desarrollo regional sustentable. Se ha desempeñado como docente en el Colegio de Estudios Científicos y Tecnológicos del Estado de Oaxaca y en la Universidad Pedagógica Nacional, unidad 201.

María del Rosario Moncada García es maestra en Administración por el Instituto Tecnológico de Oaxaca. Actualmente es estudiante del doctorado en Ciencias en Desarrollo Regional y Tecnológico en la misma institución. Su línea de investigación actual es el desarrollo regional sustentable. Entre sus últimas publicaciones destaca el artículo "El desarrollo sustentable y la centralidad de las localidades en una microrregión de pueblos originarios. El caso de la Sierra Sur de Oaxaca, México" (en coautoría con A.E. Miguel, J.C. Torres y L. Hernández), Delos: Desarrollo Local Sostenible, núm. 25, 2016. Disponible en http: //www.eumed.net/rev/delos/25/centralidad.html

Fecha de recepción: 31 de enero de 2017.

Fecha de aceptación: 27 de abril de 2017. 